\title{
COMUNICAÇÃO
}

\section{SACAROSE E pH NA GERMINAÇÃO IN VITRO DE GRÃOS DE PÓLEN DE CITROS}

\author{
Sucrose and $\mathrm{pH}$ on in vitro pollen germination of citros
}

\author{
Leila Aparecida Salles ${ }^{1}$, José Darlan Ramos ${ }^{2}$, Moacir Pasqual², Keize Pereira Junqueira ${ }^{4}$, \\ Adriano Bortolotti da Silva ${ }^{3}$
}

\begin{abstract}
RESUMO
Objetivou-se avaliar o efeito da sacarose e pH na germinação in vitro de grãos de pólen das cultivares Valência, Natal e Pêra. Para testar o efeito da sacarose, os grãos de pólen foram distribuídos uniformemente em placas de Petri contendo meio de cultura básico constituído de $10 \mathrm{gL}^{-1}$ de ágar, $800 \mathrm{mgL}^{-1}$ de nitrato de cálcio e $200 \mathrm{mgL}^{-1}$ de ácido bórico, acrescido de sacarose $(0,50,100,150$ e $200 \mathrm{gL}^{-1}$ ). Para verificação do $\mathrm{pH}$ satisfatório, os grãos de pólen foram inoculados em meio de cultura contendo $10 \mathrm{gL}^{-1} \mathrm{de}_{\text {ágar e } 800 \mathrm{mgL}^{-1} \mathrm{de}}$ nitrato de cálcio, $200 \mathrm{mgL}^{-1}$ de ácido bórico, $100 \mathrm{gL}^{-1}$ de sacarose e $\mathrm{pH}$ de 3,5; 4,0; 4,5; 5,0; 5,5; 6,0; 6,5. Após inoculação, os grãos de pólen foram incubados em $\mathrm{BOD}$ a $25^{\circ} \mathrm{C}$ por 12 horas. A porcentagem de germinação foi obtida com auxílio de microscópio óptico com objetiva de $10 \mathrm{X}$. Para todas as cultivares estudadas, a maior porcentagem de germinação foi obtida com $100 \mathrm{gL}^{-1}$ de sacarose e o maior número de grãos de pólen germinados foi verificado em $\mathrm{pH}$ 6,5, sendo observado que maiores valores de $\mathrm{pH}$ aumentaram também a quantidade de polens estourados para as cultivares Natal e Pêra e diminuíram para Valência.
\end{abstract}

Termos para indexação: Citrus sinensis, Palinologia, Cultura de tecidos, Melhoramento genético.

\begin{abstract}
This work was carried out in order to evaluate the effect of sucrose and $\mathrm{pH}$ on in vitro pollen germination of cultivars Valencia, Natal

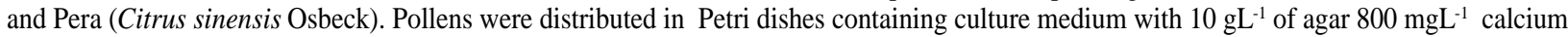
nitrate, $200 \mathrm{mgL}^{-1}$ boric acid, added of sucrose $\left(0,50,100,150\right.$ and $\left.200 \mathrm{gL}^{-1}\right)$ In order to verify the satisfactory $\mathrm{pH}$, the pollen were inoculated in culture middle containing 10 agar $\mathrm{gL}^{-1}$ and $800 \mathrm{mgL}^{-1}$ calcium nitrate, $200 \mathrm{mgL}^{-1}$ acid bórico, 100 sucrose gL $\mathrm{gL}^{-1}$ and values of 3,5; 4,0; 4,$5 ; 5,0 ; 5,5 ; 6,0 ; 6,5$. After inoculation, pollen were incubated at $25^{\circ} \mathrm{C}$ for 12 hours B.O.D. The largest germination percentage was obtained with an aid of optical microscope with lens of $10 \mathrm{X}$. For all the studied varieties, the largest germination percentage was obtained with $100 \mathrm{gL}^{-1}$ of sucrose and the largest number pollen germinated was verified at $\mathrm{pH} 6,5$, being observed that for larger $\mathrm{pH}$ the values of the amount of pollens burst also increased for the cultivars Natal and Pera and they decreased for Valencia.
\end{abstract}

Index terms: Citrus sinensis, Palinology, Tissue culture, Improvement varieties.

(Recebido para publicação em 3 de outubro de 2003 e aprovado em 22 de abril de 2005)

Dados sobre a viabilidade e o desenvolvimento de grãos de pólen são fundamentais para trabalhos de biologia reprodutiva e melhoramento genético de citros, pois permitem maior segurança nos cruzamentos, que são realizados com a finalidade de gerar novos híbridos e/ou aumentar a viabilidade. Várias pesquisas têm sido conduzidas a fim de estabelecer e padronizar meios de cultura e condições ambientais para avaliar a viabilidade de pólen em diversas espécies (NUNES et al., 2001).

A germinação de grãos de pólen in vitro permite verificar a sua viabilidade, sendo de grande importância em programas de melhoramento de frutíferas. O método geral consiste em germinar uma pequena amostra num meio apropriado e observar em microscópio, depois de determinado período, o número de grãos que produzem tubo polínico. A maior parte dos tubos polínicos tem seu crescimento interrompido antes de obter o tamanho normalmente alcançado no estigma. A composição do meio e o pH estão entre os fatores que afetam a sua germinação. Os grãos de pólen das angiospermas invariavelmente precisam de uma fonte de carbono, de boro e, frequientemente, de outros nutrientes para promover a sua germinação (GALLETTA, 1983).

Os principais componentes do meio de cultura para a germinação de pólen têm sido os diferentes tipos e concentrações de açúcares e distintas concentrações de

${ }^{1}$ Engenheira Agrônoma, mestre em Fitotecnia DAG - Universidade Federal de Lavras/UFLA - Cx. P. 3037 - 37.200-000 - Lavras, MG leilapio@ufla.br

2Professor Doutor DAG - Universidade Federal de Lavras/UFLA - Cx. P. 3037 - 37.200-000 - Lavras, MG - darlan@ufla.br

${ }^{3}$ Engenheiro Agrônomo, doutorando em Fitotecnia DAG - Universidade Federal de Lavras/UFLA - Cx. P. 3037 - $37.200-000$ - Lavras, MG.

${ }^{4}$ Acadêmica do curso de Agronomia - Universidade Federal de Lavras/UFLA - Cx. P. 3037 - 37.200-000 - Lavras, MG. 
boro (MIRANDA \& CLEMENT, 1990). O açúcar empregado no meio de cultura tem por finalidade proporcionar o equilíbrio osmótico entre o pólen e a solução de germinação e fornecer energia para auxiliar o processo de desenvolvimento do tubo polínico (STANLEY \& LINSKENS, 1974).

Kobayashi et al. (1991) observaram 50\% de germinação de grãos de pólen de um híbrido de Citrus sinensis x Poncirus trifoliata utilizando meio de cultura contendo $20 \%$ de sacarose. Diferentes concentrações de glicose foram testadas em inúmeras variedades de Citrus, sendo que melhores resultados em germinação de grão de pólen foram obtidos com $150 \mathrm{gL}^{-1}$ de glicose, apresentando em média 59\% de germinação (BUTT et al., 1993).

Objetivou-se neste trabalho testar concentrações de sacarose, bem como os níveis de $\mathrm{pH}$ para a germinação de grãos de pólen das variedades Pêra, Natal e Valência.

O trabalho foi realizado no Laboratório de Cultura de Tecidos Vegetais do Departamento de Agricultura da Universidade Federal de Lavras, UFLA. Foram coletadas flores no estádio balão de plantas sadias das cultivares Valência, Natal e Pêra (Citrus sinensis Osbeck) do Banco de Germoplasma do Pomar da UFLA. As anteras foram retiradas e colocadas em placas de Petri com papel de filtro a uma temperatura de $26^{\circ} \mathrm{C}$, durante 24 horas, para a sua completa deiscência.

Foram instalados e conduzidos dois experimentos, sendo que no primeiro deles o meio de cultura utilizado foi constituído de $10 \mathrm{gL}^{-1}$ de ágar e $800 \mathrm{mgL}^{-1}$ de nitrato de cálcio, $200 \mathrm{mgL}^{-1}$ de ácido bórico e $100 \mathrm{gL}^{-1}$ de sacarose e os tratamentos foram compostos de diferentes níveis de $\mathrm{pH}(3,5 ; 4,0 ; 4,5 ; 5,0 ; 5,5 ; 6,0 ; 6,5)$.

No segundo, utilizou-se o mesmo meio de cultura básico com pH ajustado para 6,5, acrescido de diferentes concentrações de sacarose $\left(0,50,100,150\right.$ e $\left.200 \mathrm{gL}^{-1}\right)$. Após preparo, os meios de cultura foram vertidos na quantidade de $10 \mathrm{ml}$ por placas de Petri.

Para ambos experimentos, o pólen de cada variedade foi distribuído sobre a superfície do meio com o auxílio de um pincel de modo a promover uma distribuição uniforme do material. Após inoculação, os tratamentos foram incubados em estufa tipo B.O.D. a $25^{\circ} \mathrm{C}$ e iluminação constante de 24 horas de intensidade luminosa. O delineamento experimental utilizado foi inteiramente casualizado com quatro repetições, realizando-se a contagem de 100 grãos de pólen por repetição.

Para realizar a contagem e estimar a porcentagem de grãos de pólen germinados, utilizou-se microscópio óptico com objetiva de $10 \mathrm{X}$. Considerou-se germinados os grãos de pólen cujo comprimento do tubo polínico tivesse ultrapassado o diâmetro do próprio grão de pólen, após 12 horas de incubação.

De acordo com o resumo da análise de variância detectou-se que houve diferença significativa para os diferentes níveis de $\mathrm{pH}$ e variedades, bem como a interação dos fatores estudados ao nível de $1 \%$ de probabilidade, conforme a Tabela 1 .

TABELA 1 - Análise de variância para as variáveis grãos de pólen estourados e grãos de pólen germinados de cultivares cítricas submetidas a diferentes níveis de $\mathrm{pH}$.

\begin{tabular}{lccc}
\hline \multirow{2}{*}{ Causas de variação } & \multirow{2}{*}{ GL } & \multicolumn{2}{c}{ Quadrado médio } \\
\cline { 3 - 4 } & & Germinados $(\%)$ & Estourados (\%) \\
\hline cultivares & 2 & $91,906^{* *}$ & $88,559^{* *}$ \\
$\mathrm{pH}$ & 6 & $44,653^{* *}$ & $17,106^{* *}$ \\
Cul. X pH. & 12 & $17,002^{* *}$ & $42,019^{* *}$ \\
Resíduo & 63 & 6,091 & 2,963 \\
\hline C.V. $(\%)$ & & 37,18 & 41,82 \\
\hline Média Geral (\%) & & 6,638 & 4,117 \\
\hline
\end{tabular}

** significativos ao nível de $1 \%$ de probabilidade. 
Este experimento constituiu na determinação do nível de $\mathrm{pH}$ que expressasse a mais alta porcentagem de grãos de pólen que germinados, ou seja, aqueles que tivessem seus tubos polínicos emitidos. Foram considerados germinados os grãos de pólen que apresentaram comprimento do tubo polínico igual ou superior ao diâmetro do próprio pólen (PASQUAL et al., 1982).

A Figura 1A representa o número de grãos de pólen germinados em diferentes níveis de $\mathrm{pH}$, podendo-se notar que há tendência de crescimento linear à medida em que o pH sobe até o nível de 6,5, para as cultivares Pêra e Natal. Entretanto, para a cultivar Valência, melhores resultados foram obtidos com $\mathrm{pH}$ em torno de 5. A partir desses resultados verifica-se que o nível de $\mathrm{pH}$ estimulou marcadamente o processo de germinação de pólen concordando com as observações de Brewbaker \& Kwack (1963) e Stanley \& Linskens (1974) os quais mostraram que o $\mathrm{pH}$ do meio de cultura influencia o processo da indução de germinação de pólen.

$\mathrm{Na}$ Figura 1B, observou-se que o incremento de $\mathrm{pH}$ aumentou a quantidade de grãos de pólen estourados para cultivares Natal e Pêra, e diminuiu para Valência. Estes resultados, de certa forma, validam os obtidos na variável germinação de pólen.

A importância da determinação do pH ideal nos processos fisiológicos que envolvem os grãos de pólen está associada a maior porcentagem de germinação que estes possam oferecer, garantindo maiores chances de fertilização e, conseqüentemente, maiores frutificações e melhor índice de produção no campo.

Para o experimento que testou diferentes concentrações de sacarose, a análise de variância mostrou que houve diferença significativa para os fatores estudados e suas interações, exceto para o fator cultivar.
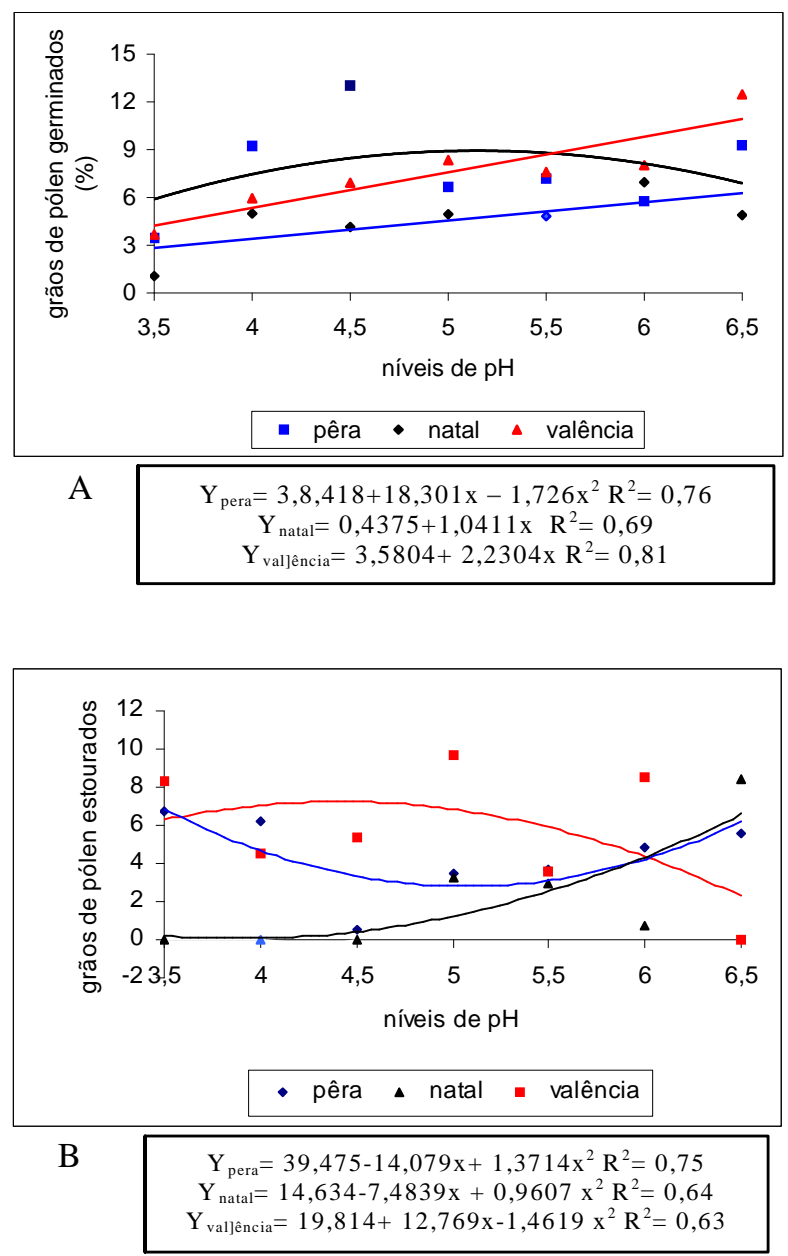

FIGURA 1 - Porcentagem de grãos de pólen germinados (A) e estourados (B) de cultivares cítricas em diferentes níveis de $\mathrm{pH}$. UFLA, 2003.

TABELA 2 - Análise de variância para as variáveis grãos de pólen estourados e grãos de pólen germinados de cultivares cítricas submetidas a diferentes concentrações de sacarose. UFLA, 2003.

\begin{tabular}{lccc}
\hline \multirow{2}{*}{ Causas de variação } & \multirow{2}{*}{ GL } & \multicolumn{2}{c}{ Quadrado médio } \\
\cline { 3 - 4 } & & Germinados $(\%)$ & Estourados $(\%)$ \\
\hline cultivares & 2 & $7,826 \mathrm{~ns}$ & $148,336^{* *}$ \\
Sacarose & 4 & $107,863^{* *}$ & $67,165^{* *}$ \\
Cul. X Sac. & 8 & $14,526^{* *}$ & $17,731^{*}$ \\
Resíduo & 45 & 3,545 & 8,091 \\
\hline C.V. $(\%)$ & & 42,03 & 55,63 \\
\hline Média Geral (\%) & & 4,480 & 5,113 \\
\hline
\end{tabular}

* e ** significativos aos níveis de 5 e $1 \%$ de probabilidade respectivamente. 
As cultivares apresentaram um comportamento semelhante, sendo que o melhor resultado foi obtido na concentração de $100 \mathrm{gL}^{-1}$ de sacarose, a partir da qual houve um decréscimo na porcentagem de grãos de pólen germinados (Figura 2A). Estes resultados concordam com a maioria dos autores, que afirmam que a sacarose é um dos componentes necessários para a germinação de pólen e também exerce a função de equilíbrio osmótico da solução, além de fornecer energia necessária para o crescimento do tubo polínico (GALLETTA, 1983; MIRANDA \& CLEMENT, 1990; STANLEY \& LINSKENS, 1974). Kobayashi et al. (1991) utilizaram concentração de $200 \mathrm{gL}^{-1}$ de sacarose para obter maior germinação de grão de pólen de um híbrido de Citrus sinensis x Poncirus trifoliata; Butt et al. (1993) obtiveram melhores resultados em germinação de grão de pólen com $150 \mathrm{gL}^{-1}$ de glicose para várias espécies de citros. Possivelmente essa diferença de concentração pode ser explicada por se tratar de genótipos diferentes. Em contrapartida, Bhattacharya \& Mandal (1999), trabalhando com cássia, obteve germinação de grãos de pólen utilizando meio de cultura com $100 \mathrm{gL}^{-1} \mathrm{de}$ sacarose. Derin \& Eti (2001) observaram que maiores taxas para germinação de romã foram obtidas em meio de cultura contendo $10 \mathrm{gL}^{-1}$ de sacarose. De maneira geral, pode-se dizer que, para as diferentes espécies, a concentração para a germinação de grão de pólen varia entre 100 e $200 \mathrm{gL}^{-1}$ de sacarose.

Pela Figura 2B observa-se a porcentagem de grãos de pólen estourados em diferentes concentrações de sacarose. Pode-se observar uma tendência bastante similar entre as variedades analisadas. A menor porcentagem de grãos de pólen estourados foi obtida com a concentração de $100 \mathrm{gL}^{-1}$, de maneira semelhante à variável analisada anteriormente. Nas menores concentrações de sacarose, houve os maiores índices de grãos de pólen estourados, evidenciando a necessidade do ajuste da concentração de sacarose para a germinação in vitro de pólen de laranjeira. Segundo Akamine \& Girolami (1959), tubos polínicos se rompem devido, entre outros fatores, a alta umidade e a variação do meio, ocasionada pelo aumento da pressão osmótica e pela baixa resistência da parede celular.

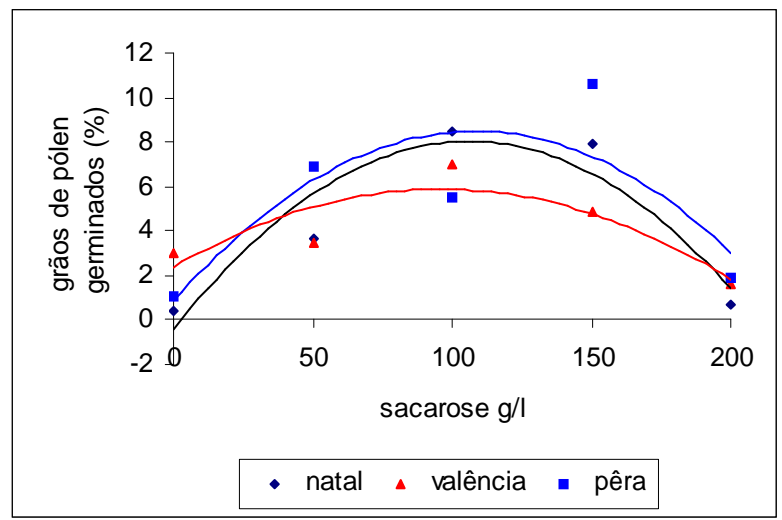

A Ynatal $=0,4457+0,1597 x-0,0008 x^{2} R^{2}=0,88$ Yvalência $=2,4286+0,0727 x-0,0004 x^{2} R^{2}=0,80$ Ypêra $=0,8586+0,1407 x-0,0006 x^{2} R^{2}=0,70$

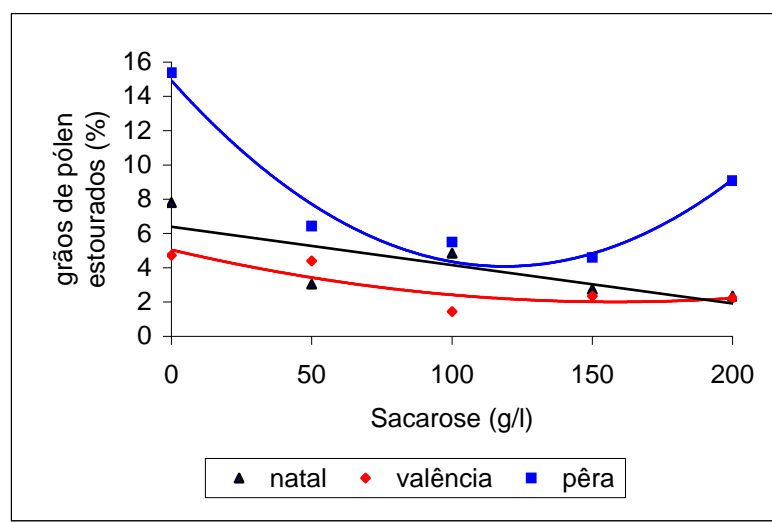

B $\begin{aligned} & \text { Ynatal }=6,265-0,0215 \times \mathrm{R}^{2}=0,69 \\ & \text { Yvalência }=5,0471-0,0384 \mathrm{x}-0,0001 \mathrm{x}^{2} \mathrm{R}^{2}=0,75 \\ & \text { Ypêra }=14,919-0,1824 \mathrm{x}-0,0008 \mathrm{x}^{2} \mathrm{R}^{2}=0,96\end{aligned}$

FIGURA 2 - Porcentagem de grãos de pólen germinados (A) e estourados (B) de cultivares cítricas em diferentes concentrações de sacarose. UFLA, 2003. 
Nas condições em que o trabalho foi realizado, permite as seguintes conclusões:

a) À medida que se eleva o valor do pH até o nível de 6,5, aumenta a quantidade de grãos de pólen germinados, exceto para a cultivar Pêra.

b) A quantidade de grãos de pólen estourados é maior em pH 6,5 para as cultivares Natal e Pêra e menor para Valência.

c) $\mathrm{O}$ meio de germinação contendo $100 \mathrm{gL}^{-1} \mathrm{de}$ sacarose proporcionou as maiores porcentagens de germinação de grãos de pólen para todas as cultivares testadas.

\section{REFERÊNCIAS BIBLIOGRÁFICAS}

AKAMINE, E. K.; GIROLAMI, G. Pollination and fruit set in the yellow passion fruit. Honolulli: University of Hawaii, 1959. 44 p. (Technical bulletin, 39).

BHATTACHARYA, A.; MANDAL, S. Loss of pollen viability of Cassia siamea Lamk. following treatment with arsenic. Journal-of-Environmental-Biology, Santiniketan, v. 20, n. 1, p. 67-69, 1999.

BREWBAKER, J. L.; KWACK, B. H. The essential role of calcium ion pollen germination and pollen tube growth. American Journal of Botany, Lancaster, v. 50, n. 9 p. 859$865,1963$.

BUTT, S. J.; YUSUF, A.; ALI, S.; KHAN, M. A. In-vitro studies on viability and germination of pollen in various citrus species. Pakistan-Journal-of-Scientific-andIndustrial-Research, Rawalpindi, v. 36, n. 10, p. 432-434, 1993.
DERIN, K.; ETI, S. Determination of pollen quality, quantity and effect of cross pollination on the fruit set and quality in the pomegranate. Turkish-Journal-of-Agriculture-andForestry, Adana, v. 25, n. 3, p. 169-173, 2001.

GALLETA, G. J. Pollen and seed management. In: MOORE, J. N.; JANICK, J. Methods in fruits breeding. Indiana: [s.n.], 1983. p. 23-47.

KOBAYASHI, S.; OIYAMA, I.; YOSHINAGA, K.; OHGAWARA, T.; ISHII, S. Fertility in an intergeneric somatic hybrid plant of Rutaceae. HortScience, Hiroshima, v. 26, n. 2, p. 207, 1991.

MIRANDA, P. A.; CLEMENT, C. R. Germination and storange of pejibaye (Bactris gasipaes) palmae pollen. Revista de Biologia Tropical, San José, v. 38, n. 1, p. 29-33, 1990.

NUNES, J. C. de O.; DANTAS, A. C. de M.; PEDROTTI, E. L.; ORTH, A. I.; GUERRA, M. P. Germinação de pólen in vitro e receptividade do estigma em macieira cvs. Fuji e Golden Delicious. Revista Brasileira de Fruticultura, Jaboticabal, v. 23, n. 1, p. 35-39, 2001.

PASQUAL, M.; PETRI, J. L.; MATTOS, C. S. Polinização da macieira III: cultivares BR-1 e Mollies Delicious. Pesquisa Agropecuária Brasileira, Brasília, v. 17, n. 10, p. 1477-1481, 1982.

StAnley, R. G.; LINSKENS, H. F. Pollen: biology, biochemistry and management. New York: Springer-Verlag, 1974. $172 \mathrm{p}$. 